\title{
The Acreemagnosia Measurement: Psychometric evaluation of a new assessment of the loss of financial knowledge.
}

\author{
Irina Kozlova ${ }^{1} \bowtie$, Tom Booth ${ }^{(2,3)}$, Mario Alfredo Parra ${ }^{(3-6)}$, Sergio Della Sala ${ }^{(1,3)}$
}

(1) Human Cognitive Neuroscience, Psychology, University of Edinburgh, UK

(2) Department of Psychology, University of Edinburgh, UK.

(3) Centre for Cognitive Ageing and Cognitive Epidemiology, University of Edinburgh, UK

(4) School of Psychological Sciences and Health, University of Strathclyde, Glasgow, UK

(5) Alzheimer's Scotland Dementia Research Centre, Edinburgh University, UK

(6) Autonomous University of the Caribbean, Barranquilla, Colombia

Correspondence concerning this article should be addressed to Irina Kozlova, Human

Cognitive Neuroscience, Psychology, University of Edinburgh, UK. 7 George Square, Edinburgh, EH8 9JZ, Email:I.Kozlova@sms.ed.ac.uk 


\begin{abstract}
Background and Objectives Impairment in financial management abilities, which we label "Acreemagnosia", is an early symptom of older people experiencing cognitive decline. This article describes the development and psychometric evaluation of The Acreemagnosia Measurement (TAM) which assesses everyday financial abilities and could be applied to older people who are healthy, experiencing MCI, or affected by dementia. TAM is a multi-item scale combining subjective, objective and performance-based measures that assess abilities and awareness across a wide range of financial functions and tasks. Methods Item Response theory (IRT) was applied to examine the structure and item performance, as well as to determine scale reliability. Results Analysis suggests that TAM is measuring most reliably at low to average levels of financial ability which is appropriate for testing elderly retired people, experiencing MCI, or affected by dementia. All the items in TAM show a good discrimination capacity. Differential Item Functioning (DIF) analysis did not show any gender or age bias. Discussion
\end{abstract} TAM is a useful tool for the measurement of everyday financial abilities in older people.

Key words: financial abilities, financial awareness, scale development, Item Response theory, Differential Item Functioning 


\section{Introduction}

Acreemagnosia (from the Ancient Greek $\dot{\alpha}$ - (a-, "lack of"), $\chi \rho \eta \dot{\mu} \mu \alpha$ (creema, "money") and

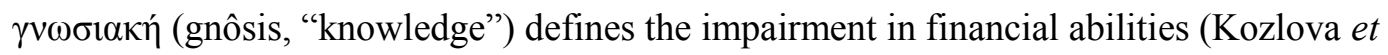
$a l ., 2017)$. Its presence is argued to be an early symptom of dementia (Marson et al., 2000, Willis, 1996) and a strong predictor of future cognitive decline (Chiong et al., Peres et al., 2008). Testifying before the Elder Justice Coordinating Council (EJCC) (Washington testimony, April 27, 2016) Dr. J.Karlawish, Co-Director of the Penn Memory Centre, said: "Among the first signs of cognitive changes caused by diseases such as Alzheimer's disease, and cognitive aging as well, are changes in our capacity to manage our finances" and urged to assure the financial security of ageing people.

Despite its clinical and legal relevance, little attention has been paid to this frequent symptom, mainly due to the lack of available instruments to assess it. The aim of this study was to devise an instrument which can assess the decline in financial abilities that characterizes Acreemagnosia. In addition to the new instrument, we present normative data from a sizeble group of healthy volunteers.

Clinicians routinely check for financial competence relying on clinical interviews and Activities of Daily Living/Instrumental Activities of Daily Living(ADL/IADL) scales, which do not thoroughly explore financial abilities (Kershaw and Webber, 2008). The most widely used ADL/IADL scales in clinical settings include only a few items inquiring about financial competence (Bucks et al., 1996; Gelinas et al., 1999; Lawton and Brody, 1969). Moreover, these few items are rather dated. Technological advances (computers, smart phones, tablets), changes in shopping styles (online shopping, online food order or tickets booking), and financial affairs (more complex banking and investment systems, ATM machines and online banking), can pose challenges to older people, especially to those experiencing cognitive decline. These are not considered in ADL/IADL scales (Muñoz-Neira et al., 2012; Rosenberg et al, 2009). Nevertheless, some suggestions could be derived from studies that aimed at differentiating healthy ageing from MCI/AD patients using ADL/IADL scales. These studies demonstrated that activities such as shopping, transportation, managing medication and handling finances were the best suited for this purpose (Aretouli and Brandt, 2010; Bangen et al., 2010; Barberger-Gateau et al., 1992; Barberger-Gateau et al., 1996b; Gold, 2012; Kim et al., 2009; Njegovan et al., 2001; Nygård, 2003; Pedrosa et al., 2010; Reppermund et al., 2011; Willis, 1996). The identification of deficits in these activities has been claimed to predict dementia 3-5 years prior to the onset of clinically detectable symptoms (BarbergerGateau et al., 1996a; Cromwell et al., 2003; Pérès, 2008). Further data suggest that managing 
finances is among the earliest IADL impairment in MCI (Gold, 2012; Griffith et al., 2003; Kim et al., 2009; Marson et al., 2000; Sikkes et al., 2011).

Finally, there is growing concern that clinical neuropsychological assessment is unsuitable as a proxy for evaluating financial ability (Kershaw and Webber, 2008; Stebnicki, 1997). Indeed, there is evidence that people who perform well on psychometric tests may still perform poorly on financial competence tests (Bechara et al., 1994). Given the considerations above, specific assessment of financial abilities is of a paramount importance not only because it appears to be a sensitive and early functional method to detect incipient dementia, but also because a reduced competence to look after one's own finances is a major risk of being financially exploited or abused (Acierno et al., 2010; James et al., 2014; Kemp and Mosqueda, 2005; Reiboldt and Vogel, 2003; Tueth, 2000), hence losing independence (De Vriendt et al., 2012; James et al., 2014;Schmitter-Edgecombe et al., 2011; Smith, 2000; Tueth, 2000).

Therefore, there is the unmet need for a new instrument, which could aid the identification of Acreemagnosia and quantify its severity. Such instrument should be informative when assessing financial competence in normal ageing, avoiding ceiling effects by including tasks with different levels of complexity (easy, moderate and difficult items). This would allow clinicians and researchers to track financial decline and monitor the development of symptoms over time, help patients to live as independently as possible for longer, and importantly identify those individuals who are potentially vulnerable to financial scams. In order to improve construct validity and considering the risk of bias and proneness to underestimation in caregivers' appraisals of patients' functional abilities (Cramer et al., 2004; Fieo et al., 2011), such a tool should incorporate informant-based, self-report and performance-based measures that would complement each other. A psychometrically valid tool should incorporate unidimensional items which measure specific constructs as well as items which measure more than one construct, referred to as complex (Reckase, 2009). The new instrument should refine conceptual aspects underlying both simple and complex items not addressed by existing scales.

There are several scales to specifically evaluate financial abilities that have been previously reported (See Table 1 in the Supplementary material for more details). Based on the notion that financial competence is a multidimensional concept comprising conceptual, pragmatic, and judgmental knowledge aspects, Marson et al. (2000) developed the "Financial Capacity Instrument" (FCI). FCI was the first instrument specifically designed to assess financial abilities in people with dementia. However, the tool has a very limited clinical utility as it encompasses more than 100 items and takes more than an hour to administer. To address this 
issue the authors have devised two shorter versions of the instrument. The Semi-Structured Clinical Interview for Financial Capacity (SCIFC) (Marson et al., 2009) is proposed as a brief (25 minutes) financial clinical assessment tool and comprises the same domains of the FCI scale. The other instrument is the Financial Capacity Instrument - Short Form (FCI-SF) which is also a brief (less than 15 minutes) clinical screening tool (Gerstenecker et al., 2016) assessing financial competence and calculation. Based on the FCI, Wadley et al. (2003) developed an instrument that comprises two components, the Prior Financial Capacity Form and the Current Financial Capacity Form. They incorporate the same domains of FCI aiming at evaluating prior and current financial abilities in $\mathrm{AD}$ patients. The reference point for the prior functioning is assumed to be when the examinee was best at managing personal financial affairs. The FCI and its derived tools, which are all based on the US monetary system, have been fully validated and standardised on MCI and AD patients. However, none of these different versions of the FCI are available for use ${ }^{1}$.

The other scale reported in the literature is the "Financial Competence Assessment Inventory" (FCAI) developed by Kershaw and Webber (2008). The scale, which was developed to investigate the legal component of financial competence based on legal criteria used in the United States and Australia, assesses four domains: "understanding", "appreciation", "reasoning", and "expressing a choice." The FCAI comprises 41 items (tasks and questions) related to financial abilities and consists of 6 subscales. The instrument was never published in full. Only a brief description of the validity of the tool was reported in the manuscript without detailing the actual questions for each of the domains. This questionnaire is unavailable for public use ${ }^{2}$.

The Measure of Awareness of Financial Skills (MAFS) devised by Cramer and colleagues (2004) was designed so awareness of financial abilities is a central component of financial competence as loss of awareness is linked to the severity of cognitive impairment and risk of progression from MCI to AD (Tabert et al., 2002). The instrument contains 34 questions about different financial tasks; participants are asked to rate, on a four-point scale, the amount of difficulty they experience when performing each of these tasks and the amount of help they would need to perform them correctly. The questionnaire takes 1.5 hours for patients to complete and 20 minutes for informants, which renders its clinical utility questionable. There is only one paper published on the instrument (Cramer et al., 2004). The instrument is not

\footnotetext{
${ }^{1}$ The authors were contacted and replied that the instrument will be available to buy in the future

2 The authors were contacted and replied that the instrument was created for the purpose of their research and not available for use
} 
freely accessible for use ${ }^{3}$. It is validated on the Canadian population (See Table 1 in the Supplementary material for more details on each developed instrument).

Considering the above discussed needs and gaps, we developed a new instrument that we called The Acreemagnosia Measurement (TAM) (For more details on the initial instrument development, see the Supplementary material). Our goal was to create a psychometrically rigorous instrument that would assess abilities and awareness across a wide range of financial functions which could be applied to older people who are healthy, experiencing MCI, or affected by dementia. In this paper we describe the development and psychometric evaluation of this instrument.

\section{Investigating the psychometric properties of the practical part of TAM}

\section{Objectives}

The primary aim of the study was to investigate the psychometric properties of the TAM scale. In particular, our analyses focussed on scale dimensionality, item performance in the whole sample, differences in performance across key demographic splits (gender and age), and scale reliability. The goal was to identify those items which may be reasonably removed or modified in later scale developments.

\section{Participants}

Three hundred and twenty-two participants recruited online and from the university volunteer panel completed TAM online. For the analysis we partitioned out participants sample into younger than 65 years old and above 65 (see Figure 1). The partition of younger and older respondents was based on both theoretical consideration of key ages for MCI and dementia (Geda, 2012), and on practical limitations to maintain sufficient sample sizes in both groups.

\section{----- Insert Figure 1 about here -----}

\section{Analyses}

The psychometric evaluation of the scale followed a series of steps to evaluate item performance using Item Response Theory (IRT) models. IRT models are ideally suited to scale development in clinical settings (Reise \& Waller, 2009).

\footnotetext{
3 The authors were contacted however without a reply
} 


\section{Step 1. Establish unidimensionality}

Dimensionality refers to understanding whether all items load onto a single latent dimension (unidimensionality), or whether subsets of items load on different latent dimensions (multidimensional). Assessing unidimensionality is an important step in IRT analyses in order to assist the selection of an appropriate model (Embretson \& Reise, 2013).

Here, the unidimensionality of the item set was established according to the combined evidence across a number of indices. First, we consider the results from parallel analysis (PA; Horn, 1965) and Velicer's minimum average partial (MAP: Velicer, 1976) test. Both tests have performed well in simulation studies investigating methods for scale dimensionality. We use PA and MAP to define a plausible range for the appropriate dimensionality of the data, where PA will set the upper bound, and MAP the lower bound.

Next, we considered model fit comparisons based on exploratory factor analytic solutions. We considered both overall fit using empirically supported guidelines (Hu \& Bentler, 1998), and the difference in fit between models with a sequentially increasing number of factors. Specifically, a model fits well if the root-mean-square error approximation index (RMSEA, Steiger \& Lind, 1980) is $<0.06$ and the Tucker-Lewis fit index (TLI; Tucker \& Lewis, 1973) is $\geq 0.95$. We also considered the improvement in fit demonstrated by the addition of an extra factor. Alongside model fit, the ratio of the first and the second eigenvalues were considered, with ratio's more than 3.0 providing indicative support for unidimensionality (Slocum-Gori \& Bruno, 2011). Finally, we considered the theoretical conherence of factor solutions with more than one factor, versus the theorized structure of TAM.

Once an appropriate dimensionality had been established, we used the results from these factor models to remove items which did not appear to relate to any other items. This was assessed based on low item factor loadings, with items loading below 0.30 considered for removal from subsequent IRT analysis.

All analyses were performed using R version 3.3.3 (R Core Team, 2017) using the packages 'psych' (Revelle, 2016) and 'mirt' (Chalmers, 2012).

\section{Step 2. Fitting 2PL model and assessment of item characteristic and test information curves}

After establishing latent trait uni-dimensionality, item performance was analysed using the two-parameter logistic model (2PL) that assumes that items differ both with respect to how difficult they are to answer (difficulty parameter $\left(a_{i}\right)$ ), and how well they differentiate levels of the latent trait $(\theta)$ (discrimination parameter $(b i j)$ ). Individual items were assessed for fit 
based on the S- $\chi 2$ proposed by Orlando and Thissen (2000). S- $\chi 2$ is based on a comparison of observed and model predicted item responses, given an individual's level of the latent trait $(\theta)$. Poorely fitting items were inspected with item characteristic curves (ICC). ICC is a nonlinear regression line that expresses a subject's probability of a correct response to each item. The slope of the ICC characterizes the discriminability of the item; item difficulty was characterized as the point along the theta continuum with a $50 \%$ chance of correctly answering the item. In the context of evaluating item performance of TAM, items that have large discrimination parameters and which span a range of difficulty levels will be retained.

Item difficulty and discriminability parameters, standard errors, and summary statistics were obtained using maximum-likelihood estimation. The characteristic curves for each item were plotted for visual inspection. We calculated 2PL models using the mirt() $\mathrm{R}$ package (Chalmers, 2012), and item characteristic using irtoys() R package (Partchev, 2016).

A second purpose of our IRT analyses was to explore the reliability of the total score on TAM. Reliaility in IRT differs from conventional reliability metrics such as Cronbach's alpha as with IRT models, reliability is assessed across levels of the latent ability factor $(\theta)$. For a given level of $\theta$, if the amount of information is large, it means that an individual's ability at that level can be estimated with higher precision and thus is more reliable. If the amount of information is small, it means that an individual's ability at that level cannot be estimated with precision and the estimates will be widely scattered about the true ability.

In order to investigate information across the range of measured ability, we computed the test information curve by plotting the amount of test information against ability. The curve will allow us to identify how robust the test is in estimating ability over the whole range of ability scores. In evaluating TAM, we calculate the range of ability levels that can be reliably assessed. To do this, we consider the the range within which conditional test information is greater than 10. For comparative puroposes, conditional test information of 10 approximately equates to a classical test theory reliability (Cronbach's alpha) of .90 (Embretson \& Reise, 2013, page 270).

\section{Step 3. Evaluation of differential item functioning by age and sex}

Finally, we used Differential Item Functioning (DIF) analyses to identify differences in item parameters across groups. DIF occurs when individuals who have the same standing on the latent trait do not have the same probability of item endorsement (Edelen et al, 2006). In other words, DIF analyses identify items which perform differently in different groups of individuals. Failure to identify items which show DIF can result in biased tests. Given the 
proposed use of the current measure, we investigated DIF across sex (Male vs. Female) and across age group (Younger vs. Older).

The mirt() R package (Chalmers, 2012) was used to assess DIF. We set no anchors a priori; all items were tested for DIF by adding item constraints one item at a time. In the analysis by sex, the male group was our reference group, with the mean and standard deviation of the female group estimated (focal group). In the analysis by age group, the younger participants group was our reference group, with the mean and standard deviation of the older participants estimated (focal group). The test compares parameter estimates (difficulty level and discriminability of each item) across the reference and focal group. Wald tests based on the procedure proposed by Lord (1977), providing separate chi-square statistics for the discrimination and threshold parameters for each studied item, are used to evaluate the presence of DIF. When DIF is detected, effect sizes for the threshold and/or slope parameters will aid the description and interpretation of the group differences (Steinberg \& Thissen, 2006).

\section{Item selection}

Based on the results of the whole sample and DIF analyses, items were selected for removal. Items which show DIF across either group, or which have poor discrimination in the total sample or sub-groups, were removed. Once items were removed, we re-calculated test information in order to assess whether the removal of items impacts on test reliability.

\section{Results}

\section{Step1. Establish unidimensionality}

Eigenvalues suggest one general factor: eigenvalues for first four factors were 7.83, 1.71, 1.47 and 1.28, with a large ratio between the first and the second eigenvalues (4.5) when compared to the second and third (1.16). MAP suggested a single factor, whilst PA suggested 3 factors (See Appendix A Figure 1 and 2).

Examination of model fit across the one $(\mathrm{RMSEA}=.081$, TLI $=.795)$, two $(\mathrm{RMSEA}=.064$, $\mathrm{TLI}=.852)$ and three $(\mathrm{RMSEA}=.040, \mathrm{TLI}=.91)$ factor models suggested, as expected, that fit improved as the number of factors increased. All models met minimum criteria for the RMSEA, and no models reached the minimum criteria according to the TLI. The difference in fit across models was significant $(\mathrm{p}<.001)$ according to the chi-square tests. Thus collectively, the suite of test of dimensionslity suggested between one and three factors.

In order to select between the solutions, we explored the item factor loadings. All items from 
the scale loaded significantly on one general factor with loadings above 0.3 for all items, except for three items (items 36, 37, and 38) with factor loading 0.03, 0.14, and -0.11 respectively. In the two factor solution, 4 items loaded on the second factor (items 36, 37, 38, and 46), and on the 3-factor model items 38, 39, 40, and 41 formed the third factor. Neither 2 nor 3 factor-model seem to reflect a coherent theoretical interpretation. We inspected these items more closely.

Taking all the above information into account, we retained a single factor model, primarily driven by the theoretical coherence of the model. Due to the low loadings noted above, items 36, 37 and 38 were excluded from subsequent analyses.

\section{Step 2}

\section{Items characteristics}

Table 1 reports item parameter (difficulty and discrimination) estimates and their standard errors for the 2PL model. Item discrimination parameters were between 0.53 and 4.38 . Discrimination parameters greater than 1.70 are considered large and therefore have excellent discrimination capacity (Baker, 2001, pg 34). Most of the items in the scale have a excellent discrimination. Item difficulty estimates were distributed between -1.80 and 0.19 . This indicates that a majority of items are positioned at below, or just above average (theta= 0 ) levels of performance. Item 41 has large and significant S- $\chi 2$, meaning that this item does not fit into a predicted response model. Inspecting its ICC and item discrimination, however, revealed that the item has an excellent discrimination capacity $(\mathrm{a}=2.3)$, that is why we decided to retain item 41 for further inspection.

Inspection of ICC (Figure 2) and parameter estimates indicates that Item 46 had near-zero discrimination parameter (slope is 0.14 ) and subsequently a flatter ICC, suggesting that this item was poor in discriminating between respondents and yielding minimal psychometric information. Based on these findings, item 46 was identified as a potential item for removal from the final version of TAM.

----- Insert Table 1 about here -----

----- Insert Figure 2 about here -----

Maximal information in the whole sample for the final scale (23.92) is at the trait level $(\theta)$ of -1.04 , with the reliable range of measurement (information $>10$ ) for the ability range 
between -1.89 and -0.14 (See Figure 3 in Supplementarial material). Therefore, TAM is best capturing moderately low to average levels financial abilities.

\section{Step 3. Establis DIF by age and gender- remove any items which do not have DIF by age and by gender}

Parameters estimated for the 2PL model across younger and older groups individually are provided in Table 2.

Most of the items were found to have very good discrimination abilities, with discriminating parameters ranging from 1.30 to 4.45 . Items $42-45$ in the younger sample were found to have very high difficulty and discriminating parameters $(\mathrm{d}=16.56,10.56,10.15$ and 13.24 respectively and $\mathrm{a}=12.52,9.00,7.38,15.56)$ meaning that only those in the younger group at very high levels of the latent trait get these items correct. Generally, difficulty level for most of the items on the scale for younger participants was higher than for older participants. However, despite this, based on the Wald statistics, no DIF was identified across age groups in either the discrimination or difficulty parameters (Table 2 ).

----- Insert Table 2 about here -----

Visual inspection of the item curves (Figure 3), and inspection of the item parameters in Table 2, reveals again that Item 46 has low difficulty level for both age groups and has very low discrimination.

----- Insert Figure 3 about here -----

Parameters estimated for the 2PL fit for different gender groups individually are provided in Table 3. Most of the items were found to have high discrimination parameters ranging from 0.80 to 4.18 . Again, Item 46 was found to have the lowest discrimination parameter in both gender groups. Generally, difficulty level for most of the items on the scale for male participants was higher than for female participants. However, despite this, based on the Wald statistics, no DIF was identified across gender in either the discrimination or difficulty parameters (Table 3, Figure 4).

----- Insert Table 3 about here -----

----- Insert Figure 4 about here -----

Item removal 
We eliminated all the poorly fitted items and items with poor discriminability (Items 36, 37, 38 after the first step and Item 46 after initial reliability analysis) and analyse the final, shorter scale. Maximal information in the whole sample for the final scale $(25.28)$ is at theta $=-1.07$, with the reliable range of measurement (information $>10$ ) for the ability range between -1.89 and -0.14 (See Figure 4 in in Appendix A) which is not very different from the test information curve that we initially had (See Figure 3 in Appendix A). Examination of model fit after elimination of the items for one factor model showed that the model did not meet minimum criteria for RMSEA or TLI $($ RMSEA $=.076$, TLI $=.87$ ). As removing these items add little value in improvement of the test information, we decided to retain all the items to explore further on clinical population to ensure their performance to be robust, discriminative and responsive.

\section{Discussion}

In order to assess financial knowledge researchers and clinicians are currently using ADL/IADL scales that do not sufficiently address the intricacy of everyday financial requirements. Almost every IADL scale has a question of everyday financial ability. However, these questions are usually very general inquires of the participant's problems to deal with everyday financial tasks. Another limitation across IADL scales is that they are not providing the information on whether there is a decline in performance or the testee has always had problems with finances. Lastly, commonly used ADL/IADL questionnaires inquire if the person is capable of perfoming a particular task, in other words require the assumption of ability to perform. Standard scales cannot answer that question on whether the person can actually perform the task. There are a few financial scales devised to look particularly at financial abilities, competence, and awareness. Unfortunately, these scales are unavailable for use and are not fully validated.

The aim of the study was to design a psychometrically rigorous instrument that would assess abilities and awareness across a wide range of financial functions which could be applied to older people who are healthy, experiencing MCI, or affected by dementia.

We used two-parameter IRT model to analyse the psychometric properties of the Skills part of TAM and established the best items that would describe financial abilities of participants in different age and gender groups. First, we found evidence of multidimensionality due to item clustering, but this multidimensionality did not distort the primary dimension. A unidimensional model was therefore sufficient to describe financial ability, as measured by TAM. This multidimntionality of the financial construct was supported by studies carried by Marson et al (2000) and Kershaw and Webber (2008). 
Secondly, the analysis suggests that TAM is measuring most reliably at low to average levels of financial ability, meaning that TAM is potentially a good financial measure for people with limited financial proficiency, which is in keeping with the design and intended use of the instrument with elderly retired people and people with cognitive impairment. In addition, all the items in TAM prove to have a good discrimination capacity and were distributed with respect to difficulty level within this specific discriminability range. Collectively the results suggest that TAM has initially promising psychometric properties.

Third, we assess item functioning across different gender and age groups. Results did not reveal any DIF in the scale. If there were items that would perform differently across different groups the results from the scores from males and females and from young and old adults would be incompatible. The results indicate that tendency to endorse the item should only reflect the ability level and should not be affected by variables such as gender and age. Nevertheless, these results should be interpreted with caution as they were drawn from relative small samples and thus the statistical power to detect DIF was low. Another limitation of this part of the study is that the data were gathered online and participants were self-selected; this may restrict generalizability.

In summary, financial ability is shown to be vulnerable to early effects of cognitive decline (Aretouli and Brandt, 2010; Gold 2012; Griffith et al., 2003; Kim et al., 2009; Marson et al., 2000). We designed TAM in order to address the limitations of the existing ADL/IADL scales. TAM is a multi-items measure that inquires about person's awareness of financial abilities and examine actual performance on the broad range of everyday financial tasks. The present data indicate that TAM is a promising tool for the measurement of the everyday financial abilities in frail older people. Future studies will look at the performance on TAM by patients with various level of cognitive impairment. It would serve not only in detecting early impairments but it would also help health care professionals (i.e., general practitioners, nurses, clinical psychologists) and other relevant professionals (i.e., social workers, financial or family counselors) to make an evidence-based decision about the person's everyday financial knowledge and it would allow them to follow up the patients' performance.

In order to make TAM easily accessible for a clinical, research, and public use it is made freely available here: http://www.ed.ac.uk/profile/sergio-della-sala. 


\section{References}

Acierno, R., Hernandez, M. A., Amstadter, A. B., Resnick, H. S., Steve, K., Muzzy, W., \& Kilpatrick, D. G. (2010). Prevalence and correlates of emotional, physical, sexual, and financial abuse and potential neglect in the United States: The national elder mistreatment study. American Journal of Public Health, 100(2), 292-297. http://doi.org/10.2105/AJPH.2009.163089

Aretouli, E., \& Brandt, J. (2010). Everyday functioning in mild cognitive impairment and its relationship with executive cognition. Geriatric Paychiatry, 25, 224-233. http://doi.org/10.1002/gps.2325

Army Individual Test Battery (1944). Manual of Directions and Scoring. Washington, DC: War Department, Adjutant General's Office.

Baker F. (2001). The basics of items response theory. Portsmouth, NH: Heinemann

Bangen, K. J., Jak, A. J., Schiehser, D. M., Delano-Wood, L., Tuminello, E., Han, S. D., Delis, D.C., \& Bondi, M. W. (2010). Complex activities of daily living vary by mild cognitive impairment subtype. Journal of the International Neuropsychological Society : JINS, 16(4), 630-639. http://doi.org/10.1017/S1355617710000330

Barberger-Gateau, P., Commenges, D., Gagnon, M., Letenneur, L., Sauvel, C., \& Dartigues, J.F. (1992). Instrumental activities of daily living as a screening tool for cognitive impairment and dementia in elderly community dwellers. Journal of American Geriatric Society, 40, 1129-113. https://doi-org.ezproxy.is.ed.ac.uk/10.1111/j.1532$\underline{5415.1992 . t b 01802 . x}$

Barberger-Gateau, P., Fabrigoule, C., Helmer, C., Rouch, I., \& Dartigues, J. F. (1999a). Functional impairment in instrumental activities of daily living: an early clinical sign 
of dementia? Journal of the American Geriatrics Society, 47(4), 456-462. https://doiorg.ezproxy.is.ed.ac.uk/10.1111/j.1532-5415.1999.tb07239.x

Barberger-Gateau, P., Fabrigoule, C., Rouch, I., Letenneur, L., \& Dartigues, J. F. (1999b). Neuropsychological correlates of self-reported performance in instrumental activities of daily living and prediction of dementia. The Journals of Gerontology. Series B, Psychological Sciences and Social Sciences, 54(5), P293-303. http://www.ncbi.nlm.nih.gov/pubmed/10542822

Bechara, A., Damasio, A.R., Damasio, H. \& Anderson, S.W. (1994). Insensitivity to future consequences following damage to human prefrontal cortex. Cognition. 50, 7-15. https://doi.org/10.1016/0010-0277(94)90018-3

Bucks, R.S., Ashworth, D.L., Wilcock, G.K. \& Siegfried, K. (1996). Assessment of activities of daily living in dementia: development of the Activities of Daily Living Scale. Age and Ageing, 25, $113-$

20. http://link.galegroup.com/apps/doc/A18173043/ITOF?u=ed_itw\&sid=ITOF\&xid $=2 \mathrm{c} 64174 \mathrm{~d}$.

Chalmers P. (2012). mirt: A Multidimensional Item Response Theory Package for the R Environment. Journal of Statistical Software, 48, 1-29. http://www.jstatsoft.org/v48/i06/

Chiong, W., Hsu, M., Wudka, D., Miller, B. L., \& Howard, J. (2014). Financial errors in dementia: Testing a neuroeconomic conceptual framework. Neurocase, 20(4), 389396. http://doi.org/10.1080/13554794.2013.770886

Cramer, K., Tuokko, H. A., Mateer, C. A., \& Hultsch, D. F. (2004). Measuring awareness of Financial skills: Reliability and validity of a new measure. Aging and Mental Health, 8(2), 161-171. http://doi.org/10.1080/13607860410001649581 
Cromwell, D. A., Eagar, K., \& Poulos, R. G. (2003). The performance of instrumental activities of daily living scale in screening for cognitive impairment in elderly community residents. Journal of Clinical Epidemiology, 56(2), 131-137. http://doi.org/10.1016/S0895-4356(02)00599-1

De Vriendt, P., Gorus, E., Cornelis, E., Velghe, A., Petrovic, M., \& Mets, T. (2018). The process of decline in advanced activities of daily living : a qualitative explorative study in mild cognitive impairment, (2012), 974-986. http://doi.org/10.1017/S1041610211002766

Edelen, M. O., Thissen, D., Teresi, J., Kleinman, M., \& Ocepek-Welikson, K. (2006). Identification of differential item functioning using item response theory and the likelihood-based model comparison approach. Application to the Mini-Mental State Examination. Medical Care, 44(11 Suppl 3), S134-42. http://doi.org/10.1097/01.mlr.0000245251.83359.8c

Embretson, S.E. \& Reise, S.P. (2013). Item response theory for psychologists. Lawrence Erlbaum Associates, Mahwah: NJ.

Farias, T.S., Cahn-Weiner, D., Harvey, D.J., Reed, B.R., Mungas, D., Kramer, J.H., \& Chui, H. (2009). Longitudinal changes in memory and executive functioning are associated with longitudinal change in instrumental activities of daily living in older adults. The Clinical Neuropsychologist, 23(3), 446-61. http://doi.org/10.1080/13854040802360558

Fieo, R.A., Austin, E.J., Starr, J.M., \& Deary, I.J. (2011). Calibrating ADL-IADL scales to improve measurement accuracy and to extend the disability construct into the preclinical range: a systematic review. BMC Geriatrics, 11(1), 42. http://doi.org/10.1186/1471-2318-11-42 
Geda, Y. (2012). Mild Cognitive Impairment in older adults. Current Psychiatry Reports, 14, 321-327. https://doi-org.ezproxy.is.ed.ac.uk/10.1007/s11920-012-0291-x

Gelinas, I., Gauthier, L., McIntyre, M., \& Gauthier, S. (1999). Development of a functional measure for persons with Alzheimer's disease: the disability assessment for dementia. American Journal of Occupational Therapy, 53, 471-481. doi:10.5014/ajot.53.5.471

Gerstenecker, A., Eakin, A., Triebel, K., Martin, R., Swenson-Davis, D., Petersen, R. C., \& Marson, D. (2016). Age and Education Corrected Older Adult Normative Data for a Short Form Version of the Financial Capacity Instrument. Psychol Assess, 28(6), 737-749. http://doi.org/10.1037/pas0000159.Age

Gold, D. A. (2012). An examination of instrumental activities of daily living assessment in older adults and mild cognitive impairment. Journal of Clinical and Experimental Neuropsychology, 34(1), 11-34. https://doi.org/10.1080/13803395.2011.614598

Griffith, H. R., Belue, K., Sicola, A., Krzywanski, S., Zamrini, E., Harrell, L., \& Marson, D. C. (2003). Impaired financial abilities in mild cognitive impairment: A direct assessment approach. Neurology, 60(3), 449-457. http://doi.org/10.1212/WNL.60.3.449

Grober, E., Sanders, A. E., Hall, C., \& Lipton, R. B. (2010). Free and cued selective reminding identifies very mild dementia in primary care. Alzheimer Disease and Associated Disorders, 24(3), 284-290.

http://doi.org/10.1097/WAD.0b013e3181cfc78b

Horn, J.L. (1965). A rationale and test for the number of factors in factor analysis. Psychometrika, 30, 179-185. https://doi.org/10.1007/BF02289447

Hu, L.T. \& Bentler, P.M. (1998). Fit indices in covariance structure modeling: Sensitivity to underparameterized model misspecification. Psychological Methods, 3, 424-453. 
James, B.D., Boyle, P.A. \& Bennet, D.A. (2014). Correlates of Susceptibility to Scams in Older Adults Without Dementia. Journal of Elder Abuse and Neglect, 26, 107-122. https://doi.org/10.1080/08946566.2013.821809

Kemp, B.J. \& Mosqueda, L.A. (2005). Elder financial abuse: an evaluation framework and supporting evidence. Journal of the American Geriatric Society, 53, 1123-1127. https://doi-org.ezproxy.is.ed.ac.uk/10.1111/j.1532-5415.2005.53353.x

Kim, K. R., Lee, K. S., Cheong, H. K., Eom, J. S., Oh, B. H., \& Hong, C. H. (2009). Characteristic profiles of instrumental activities of daily living in different subtypes of mild cognitive impairment. Dementia and Geriatric Cognitive Disorders, 27(3), 278285. http://doi.org/10.1159/000204765

Kozlova, I., Parra Rodrigues, M. \& Della Sala, S. (2018). Acreemagnosia (Loss of financial knowledge): A symptom of functional and cognitive loss in frail elderly. International Journal of Geriatric Psychiatry, 33, 434-435. https://doiorg.ezproxy.is.ed.ac.uk/10.1002/gps.4744

Lawton, M.P. \& Brody, E.M. (1969). Assessment of older people: self- maintaining and instrumental activities of daily living. Gerontologist, 9, 179-186. https://doi.org/10.1093/geront/9.3_Part 1.179

Lord, F. M. (1977). A study of item bias, using item characteristic curve theory. In Y. H. Poortinga (Ed.), Basic problems in cross-cultural psychology (pp. 19-29). Amsterdam: Swets and Zeitlinger.

Lusardi, A., \& Mitchell, O. (2005). Implications for Retirement Wellbeing. Michigan Retirement Research Center, Working Pa(November 2016). http://doi.org/10.2139/ssrn.881847 
Marson, D.C., Martin, R.C., Wadley, V., Randall, H., Snyder, S., Goode, P.S., Kinney, F.C., Nicholas, A.P., Steele, T., Anderson, B., Zamrini, E., Raman, R., Bartolucci, A., \& Harrell, L.E. (2009). Clinical Interview Assessment of Financial Capacity in Older Adults with Mild Cognitive Impairment and Alzheimer's Disease. Journal of American Geriatric Society, 57, 806-814. http://doi.org/10.1111/j.15325415.2009.02202.x.Clinical

Marson, D.C., Sawrie, S.M., Snyder, S., McInturff, B., Stalvey, T., Boothe, A., Aldridge, T., Chatterjee, A., \& Harrell, L. (2000). Assessing financial capacity in patients with Alzheimer's disease. A conceptual model and prototype Instrument. Archive of Neurology, 57, 877-884. doi:10.1001/archneur.57.6.877

Mioshi, E., Dawson, K., Mitchell, J., Arnold, R., \& Hodges, J. (2006). The Addenbrooke's Cognitive Examination Revised (ACE- R): A brief cognitive test battery for dementia screening. International Journal of Geriatric Psychiatry, 21(11), 1078-1085. https://doi-org.ezproxy.is.ed.ac.uk/10.1002/gps.1610

Muñoz-Neira, C., López, O. L., Riveros, R., Núñez-Huasaf, J., Flores, P., \& Slachevsky, A. (2012). The technology - activities of daily living questionnaire: a version with a technology-related subscale. Dementia and Geriatric Cognitive Disorders, 33, 36171. http://doi.org/10.1159/000338606

Njegovan, V., Hing, M. M., Mitchell, S. L., \& Molnar, F. J. (2001). The hierarchy of functional loss associated with cognitive decline in older persons. The Journals of Gerontology. Medical Sciences, 56, M638-M643. http://doi.org/10.1093/gerona/56.10.M638

Nygård, L. (2003). Instrumental activities of daily living: a stepping-stone towards Alzheimer's disease diagnosis in subjects with mild cognitive impairment? Acta 
Neurologica Scandinavica, 179, 42-46. http://doi.org/10.1034/j.1600-

0404.107.s179.8.x

Orlando, M. \& Thissen, D. (2000). Likelihood-based item fit indices for dichotomous item response theory models. Applied Psychological Measurement 24, 50-64. https://doi.org/10.1177/01466216000241003

Parra, M. A., Della, S., Logie, R. H., \& Morcom, A. M. (2014). Neuropsychologia Neural correlates of shape - color binding in visual working memory. Neuropsychologia, 52 , 27-36. http://doi.org/10.1016/j.neuropsychologia.2013.09.036

Parra, M. A., Fabi, K., Luzzi, S., Cubelli, R., Hernandez Valdez, M., \& Della Sala, S. (2015). Relational and conjunctive binding functions dissociate in short-term memory. Neurocase, 21, 56-66. http://doi.org/10.1080/13554794.2013.860177

Partchev, I. (2016). irtoys: A Collection of Functions Related to Item Response Theory (IRT). R package version 0.2.0. https://CRAN.R-project.org/package=irtoys

Pedrosa, H., De Sa, a, Guerreiro, M., Maroco, J., Simoes, M. R., Galasko, D., \& de Mendonca, a. (2010). Functional evaluation distinguishes MCI patients from healthy elderly people--the ADCS/MCI/ADL scale. The Journal of Nutrition, Health \& Aging, 14(8), 703-9. Retrieved from http://www.ncbi.nlm.nih.gov/pubmed/20922349

Pérès, K., Helmer, C., Amiela, H., Orgogozo, J.-M., Rouch, I., Dartigues, J.F., \& BarbergerGateau, P. (2008). Natural history of decline in instrumental activities of daily living performance over the 10 years preceding the clinical diagnosis of dementia: A prospective population- based study. Journal of the American Geriatric Society, 56, 37-44. http://doi.org/10.1111/j.1532-5415.2007.01499.x

Reckase, M.D. (2009). Multidimentional Item Response Theory: Statistics for Social and Behavioural Science. New York, NY: Springer. 
Reiboldt, W. \& Vogel, R.E. (2003). A critical analysis of telemarketing fraud in a gated senior community. Journal of Elderly Abuse and Neglect, 13, 21-38.

https://doi.org/10.1300/J084v13n04_02

Reppermund, S., Sachdev, P.S., Crawford, J., Kochan, N.A., Slavin, M.J., Kang, K., Trollor, J.N., Draper, B., \& Brodaty, H. (2011). The relationship of neuropsychological function to instrumental activities of daily living in mild cognitive impairment. International Journal of Geriatric Psychiatry, 26, 843-852. http://doi.org/10.1002/gps.2612

Revelle, W. (2016). psych: Procedures for Personality and Psychological Research, Northwestern University, Evanston, Illinois, USA, http://CRAN.Rproject.org/package $=$ psych Version $=1.6 .4$.

Rosenberg, L., Kottorp, A., Winblad, B., \& Nygård, L. (2009). Perceived difficulty in everyday technology use among older adults with or without cognitive deficits. Scandinavian Journal of Occupation Therapy, 16, 216-226. http://doi.org/10.3109/11038120802684299

Schmitter-Edgecombe, M., Parsey, C., \& Cook, D.J. (2011). Cognitive correlates of functional performance in older adults: comparison of self-report, direct observation, and performance-based measures. Journal of International Neuropsychological Society, 17, 853-864. http://doi.org/10.1017/S1355617711000865

Sikkes, S.A.M., Visser, P.J., Knol, D.L., De Lange-De Klerk, E.S.M., Tsolaki, M., Frisoni, G.B., Nobili, F., Spiru, L., Rigaud, A.S., Frolich, L., Rikkert, M.O., Soininen, H., Touchon, J., Wilcock, G., Boada, M., Hampel, H., Bullock, R., Vellas, B., Pijnenburg, Y.A.L., Scheltens, P., Verhey, F.R., \& Uitdehaag. B.M.J. (2011). Do instrumental activities of daily living predict dementia at 1- and 2-year follow-up? Findings from the development of screening guidelines and diagnostic criteria for 
predementia Alzheimer's disease study. Journal of American Geriatric Society, 59, 2273-2281. http://doi.org/10.1111/j.1532-5415.2011.03732.x

Slocum-Gori, S. \& Bruno, Z. (2011). Assessing the unidimensionality of psychological sclaes: using multiple criteria from factor analysis. Social Indicators Research, 102, 443-461. http://dx.doi.org.ezproxy.is.ed.ac.uk/10.1007/s11205-010-9682-8

Smith, R. (2000). Fraud and financial abuse of older persons. Current Issues in Criminal Justice, 11, 273-291. Retrieved from http://heinonlinebackup.com/hol-cgibin/get_pdf.cgi?handle=hein.journals/cicj11\&section $=30$

Sperling, R.A., Aisen, P.S., Beckett, L.A., Bennett, D.A., Craft, S., Fagan, A.M., Iwatsubo, T., Jack, C.R. Jr., Kaye, J., Montine, T.J., Park, D.C., Reiman, E.M., Rowe, C.C., Siemers, E., Stern, Y., Yaffe, K., Carrillo, M.C., Thies, B., Morrison-Bogorad, M., Wagster, M.V., \& Phelps, C.H. (2011). Toward defining the preclinical stages of Alzheimer's disease: Recommendations from the National Institute on Aging Alzheimer's Association workgroups on diagnostic guidelines for Alzheimer's disease. Alzheimer's \& Dementia, 7, 280 - 292. http://doi.org/10.1016/j.jalz.2011.03.003

Stebnicki, M.A. (1997). A conceptual framework for utilizing a functional assessment approach for determining mental capacity: A new look at informed consent in rehabilitation. Journal of Rehabilitation, 63, 32-37.

Steiger, J.H. \& Lind, J.C. (1980). Statistically based tests for the number of factors. Paper presented athte annual spring meeting of the Psychometric Society, Iowa City, IA.

Steinberg, L., \& Thissen, D. (2006). Using effect sizes for research reporting: Examples using item response theory to analyze differential item functioning. Psychological Methods, 11(4), 402-415. http://doi.org/10.1037/1082-989X.11.4.402 
Tabert, M. H., Albert, S. M., Borukhova-Milov, L., Camacho, Y., Pelton, G., Liu, X., Stern, Y., \& Devanand, D. P. (2002). Functional deficits in patients with mild cognitive impairment: Prediction of AD. Neurology, 58, 758-764.

http://doi.org/10.1212/WNL.58.5.758

Tucker, L.R. \& Lewis, C. (1973). A reliability coefficient for maximum likelihood factor analysis. Psychometrika, 38, 1-10. https://doi.org/10.1007/BF02291170

Tueth, M.J. (2000). Exposing financial exploitation of impaired elderly persons. American Journal of Geriatric Psychiatry, 8, 104-111. https://doi.org/10.1097/00019442$\underline{200005000-00004}$

Velicer, W.F. (1976). Determining the number of components from the matrix of partial correlations. Psychometrika, 41, 321-327. https://doi.org/10.1007/BF02293557

Wadley, V.G., Harrell, L.E., \& Marson, D.C. (2003). Self- and informant report of financial abilities in patients with Alzheimer's disease: Reliable and valid? Journal of the American Geriatric Society, 51, 1621-1626. http://doi.org/10.1046/j.1532$\underline{5415.2003 .51514 . x}$

Washington testimony (April 27, 2016). Retrieved November 18, 2018, from https://pennmemorycenter.org/in-washington-testimony-karlawish-calls-for-federalwhealthcare-action/

Wechsler, D. (2011). The Test of Premorbid Functioning (TOPF). San Antonio TX: The Psychological Corporation.

Willis, S.L. (1996). Everyday cognitive competence in elderly persons: conceptual issues and empirical findings. Gerontologist, 36, 595-601. https://doiorg.ezproxy.is.ed.ac.uk/10.1093/geront/36.5.595 


\section{Table 1}

Item fit statistics and Item parameter estimates (SE) of a Two-parameter Unidimensional Item Response Model

\begin{tabular}{|c|c|c|c|c|c|c|}
\hline Item & S_X2 & $\mathrm{p}$ & $b i j$ & SE & $a_{i}$ & SE \\
\hline Q25 & 9.31 & 0.59 & 1.71 & 0.27 & -1.34 & 0.16 \\
\hline Q26 & 17.19 & 0.07 & 1.54 & 0.27 & -1.8 & 0.22 \\
\hline Q27 & 10.83 & 0.54 & 1.13 & 0.19 & -1.07 & 0.18 \\
\hline Q28 & 8.39 & 0.39 & 2.22 & 0.38 & -1.55 & 0.15 \\
\hline Q29 & 5.44 & 0.90 & 1.38 & 0.23 & -1.62 & 0.21 \\
\hline Q30 & 11.61 & 0.31 & 2.02 & 0.32 & -1.30 & 0.14 \\
\hline Q31 & 7.61 & 0.66 & 2.18 & 0.34 & -1.27 & 0.13 \\
\hline Q32 & 5.87 & 0.75 & 3.11 & 0.48 & -0.84 & 0.09 \\
\hline Q33 & 3.27 & 0.97 & 2.00 & 0.31 & -1.20 & 0.13 \\
\hline Q34 & 8.4 & 0.75 & 1.17 & 0.19 & -0.84 & 0.16 \\
\hline Q35 & 13.71 & 0.32 & 0.96 & 0.17 & -0.71 & 0.10 \\
\hline Q39 & 10.68 & 0.30 & 2.25 & 0.35 & -0.12 & 0.09 \\
\hline Q40 & 6.82 & 0.74 & 1.61 & 0.26 & -0.08 & 0.10 \\
\hline Q41 & 23.30 & 0.003 & 2.30 & 0.36 & -0.37 & 0.09 \\
\hline Q42 & 4.30 & 0.37 & 4.38 & 0.88 & -1.23 & 0.09 \\
\hline Q43 & 6.96 & 0.54 & 2.95 & 0.50 & -1.30 & 0.11 \\
\hline Q44 & 14.07 & 0.08 & 2.09 & 0.38 & -1.72 & 0.18 \\
\hline Q45 & 6.35 & 0.70 & 3.45 & 0.55 & -0.87 & 0.09 \\
\hline Q46 & 5.71 & 0.93 & 0.53 & 0.14 & 0.19 & 0.24 \\
\hline Q47 & 13.53 & 0.19 & 1.94 & 0.32 & -1.45 & 0.16 \\
\hline Q48 & 14.71 & 0.19 & 1.32 & 0.23 & -1.57 & 0.21 \\
\hline
\end{tabular}

Note: $S \_X 2=$ goodness of fit index, bij = item discrimination, $a_{i}=$ item difficulty 
Table 2

Item parameters estimates and DIF results for different Age groups

\begin{tabular}{|c|c|c|c|c|c|c|c|c|c|c|}
\hline Item & & & $<65$ & & & & & $>65$ & & \\
\hline & Mean & $b i j$ & $a_{i}$ & $\begin{array}{c}\text { Total } \\
\chi^{2}(\mathrm{df})\end{array}$ & $\mathrm{p}$ & Mean & $b i j$ & $a_{i}$ & $\begin{array}{r}\text { Total } \\
\chi 2 \text { (df) } \\
\end{array}$ & $\mathrm{p}$ \\
\hline Q25 & 0.86 & 4.06 & 4.43 & 1.27 & 0.26 & 0.81 & 1.09 & 1.96 & 0.45 & 0.50 \\
\hline Q26 & 0.92 & 4.04 & 5.94 & 1.43 & 0.23 & 0.86 & 1.03 & 2.43 & 1.16 & 0.28 \\
\hline Q27 & 0.77 & 1.41 & 1.55 & -0.072 & 1.00 & 0.70 & 0.81 & 1.06 & -0.19 & 1.00 \\
\hline Q28 & 0.92 & 3.19 & 5.00 & 0.095 & 0.75 & 0.86 & 1.63 & 3.11 & -0.02 & 1.00 \\
\hline Q29 & 0.84 & 2.36 & 2.70 & 0.33 & 0.56 & 0.84 & 0.97 & 2.15 & -0.17 & 1.00 \\
\hline Q30 & 0.80 & 1.92 & 2.01 & -0.21 & 1.00 & 0.84 & 1.82 & 3.04 & -0.34 & 1.00 \\
\hline Q31 & 0.84 & 2.81 & 2.99 & -0.16 & 1.00 & 0.83 & 1.74 & 2.78 & -0.24 & 1.00 \\
\hline Q32 & 0.82 & 4.46 & 3.92 & 0.001 & 0.97 & 0.75 & 2.43 & 2.44 & -0.16 & 1.00 \\
\hline Q33 & 0.85 & 4.96 & 4.86 & 0.98 & 0.32 & 0.80 & 1.31 & 2.05 & 0.21 & 1.00 \\
\hline Q34 & 0.72 & 1.22 & 1.13 & -0.35 & 1.00 & 0.66 & 0.85 & 0.86 & -0.29 & 1.00 \\
\hline Q35 & 0.72 & 1.24 & 1.13 & 0.09 & 0.76 & 0.60 & 0.63 & 0.50 & -0.18 & 1.00 \\
\hline Q39 & 0.55 & 2.12 & 0.25 & -0.27 & 1.00 & 0.53 & 1.51 & 0.20 & -0.32 & 1.00 \\
\hline Q40 & 0.55 & 1.49 & 0.45 & -0.29 & 1.00 & 0.49 & 1.14 & -0.05 & -0.2 & 1.00 \\
\hline Q41 & 0.66 & 1.71 & 0.91 & 0.14 & 0.71 & 0.60 & 1.83 & 0.68 & -0.06 & 1.00 \\
\hline Q42 & 0.92 & 11.35 & 14.59 & 1.57 & 0.21 & 0.84 & 3.19 & 4.66 & 1.33 & 0.24 \\
\hline Q43 & 0.89 & 9.14 & 10.36 & 2.30 & 0.13 & 0.85 & 2.00 & 3.30 & 1.56 & 0.21 \\
\hline Q44 & 0.92 & 7.35 & 9.78 & 2.41 & 0.12 & 0.89 & 1.30 & 3.05 & 1.85 & 0.17 \\
\hline Q45 & 0.84 & 12.48 & 10.65 & 2.19 & 0.14 & 0.75 & 2.27 & 2.41 & 1.22 & 0.27 \\
\hline Q46 & 0.41 & 1.30 & -0.55 & 0.98 & 0.32 & 0.49 & 0.38 & -0.03 & -0.06 & 1.00 \\
\hline Q47 & 0.88 & 1.58 & 2.69 & -0.08 & 1.00 & 0.84 & 1.70 & 2.90 & -0.17 & 1.00 \\
\hline Q48 & 0.84 & 2.58 & 2.85 & 0.96 & 0.32 & 0.82 & 0.84 & 1.87 & -0.03 & 1.00 \\
\hline
\end{tabular}

Note. bij $=$ item discrimination, $a_{i}=$ item difficulty 
Table 3

Item parameters estimates and DIF results for different gender groups

\begin{tabular}{|c|c|c|c|c|c|c|c|c|c|c|}
\hline \multirow[t]{2}{*}{ Item } & \multicolumn{5}{|c|}{$M A L E$} & \multicolumn{5}{|c|}{ FEMALE } \\
\hline & Mean & $b i j$ & $a_{i}$ & $\begin{array}{c}\text { Total } \chi 2 \\
\text { (df) }\end{array}$ & $\mathrm{p}$ & Mean & $b i j$ & $a_{i}$ & $\begin{array}{c}\text { Total } \\
\chi^{2} \text { (df) }\end{array}$ & $\mathrm{p}$ \\
\hline Q25 & 0.82 & 1.76 & 2.24 & 0.12 & 0.72 & 0.79 & 1.04 & 1.55 & 0.07 & 0.79 \\
\hline Q26 & 0.84 & 1.48 & 2.24 & 0.05 & 0.82 & 0.92 & 1.23 & 3.1 & 0.04 & 0.84 \\
\hline Q27 & 0.66 & 0.83 & 0.76 & 0.05 & 0.82 & 0.78 & 0.95 & 1.45 & 0.02 & 0.89 \\
\hline Q28 & 0.86 & 2.94 & 3.61 & 0.18 & 0.67 & 0.9 & 1.53 & 3.14 & 0.09 & 0.77 \\
\hline Q29 & 0.83 & 1.18 & 1.98 & 0.06 & 0.80 & 0.83 & 0.95 & 1.85 & 0.02 & 0.89 \\
\hline Q30 & 0.81 & 2.56 & 2.71 & 0.14 & 0.70 & 0.86 & 1.33 & 2.36 & 0.05 & 0.82 \\
\hline Q31 & 0.83 & 3.20 & 3.44 & 0.15 & 0.70 & 0.85 & 1.70 & 2.56 & 0.08 & 0.78 \\
\hline Q32 & 0.72 & 3.99 & 2.54 & 0.11 & 0.74 & 0.80 & 2.34 & 2.41 & 0.00 & 1.00 \\
\hline Q33 & 0.74 & 1.89 & 1.67 & 0.02 & 0.89 & 0.88 & 1.73 & 3.06 & 0.01 & 0.92 \\
\hline Q34 & 0.68 & 1.08 & 0.92 & 0.07 & 0.78 & 0.68 & 0.69 & 0.76 & 0.05 & 0.82 \\
\hline Q35 & 0.67 & 1.22 & 0.9 & 0.29 & 0.64 & 0.63 & 0.53 & 0.46 & 0.13 & 0.72 \\
\hline Q39 & 0.49 & 2.13 & -0.06 & 0.05 & 0.81 & 0.54 & 1.46 & -0.07 & 0.01 & 0.93 \\
\hline Q40 & 0.47 & 2.11 & -0.19 & 0.17 & 0.68 & 0.58 & 1.01 & 0.22 & 0.03 & 0.87 \\
\hline Q41 & 0.55 & 3.55 & 0.37 & 0.35 & 0.55 & 0.62 & 1.32 & 0.37 & 0.02 & 0.90 \\
\hline Q42 & 0.81 & 4.39 & 4.17 & 0.13 & 0.71 & 0.90 & 2.99 & 4.87 & 0.09 & 0.76 \\
\hline Q43 & 0.84 & 2.49 & 2.98 & 0.02 & 0.88 & 0.88 & 2.73 & 4.16 & 0.02 & 0.88 \\
\hline Q44 & 0.89 & 2.30 & 3.60 & 0.08 & 0.78 & 0.90 & 1.44 & 3.04 & 0.07 & 0.78 \\
\hline Q45 & 0.69 & 3.26 & 1.84 & 0.06 & 0.81 & 0.81 & 3.78 & 3.67 & -0.01 & 1.00 \\
\hline Q46 & 0.44 & 0.59 & -0.24 & 0.36 & 0.55 & 0.51 & 0.26 & -0.01 & 0.23 & 0.63 \\
\hline Q47 & 0.81 & 2.02 & 2.32 & 0.003 & 0.95 & 0.87 & 1.96 & 3.04 & 0.01 & 0.90 \\
\hline Q48 & 0.84 & 1.40 & 2.19 & 0.03 & 0.87 & 0.87 & 1.23 & 2.30 & 0.04 & 0.85 \\
\hline
\end{tabular}

Note. $b i \mathrm{j}=$ item discrimination, $a_{i}=$ item difficulty 


\section{Figure Captions}

Figure 1

Participants distribution according to age and gender
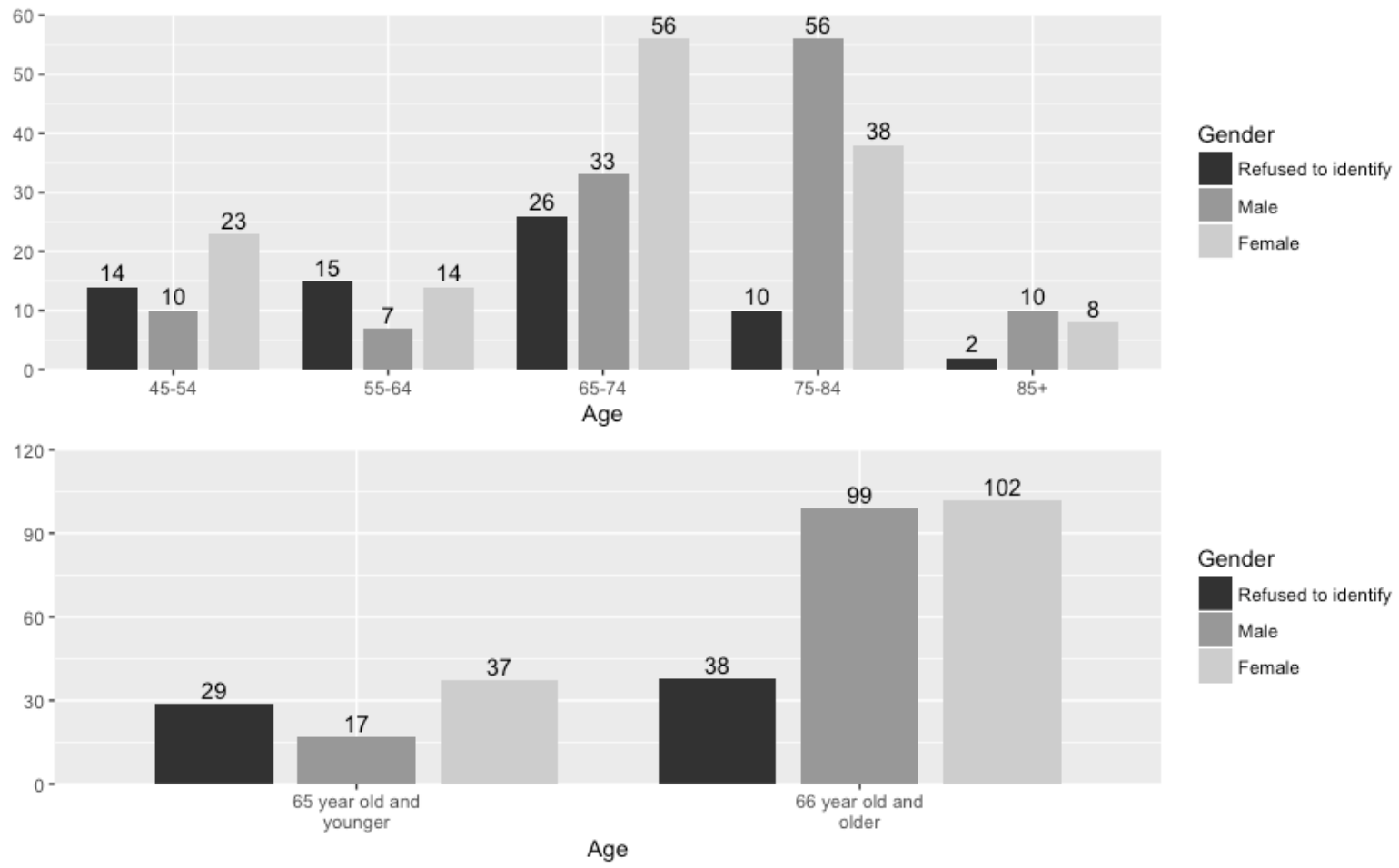
Figure 2

Item Characteristic Curves (ICC)

\section{Item trace lines}

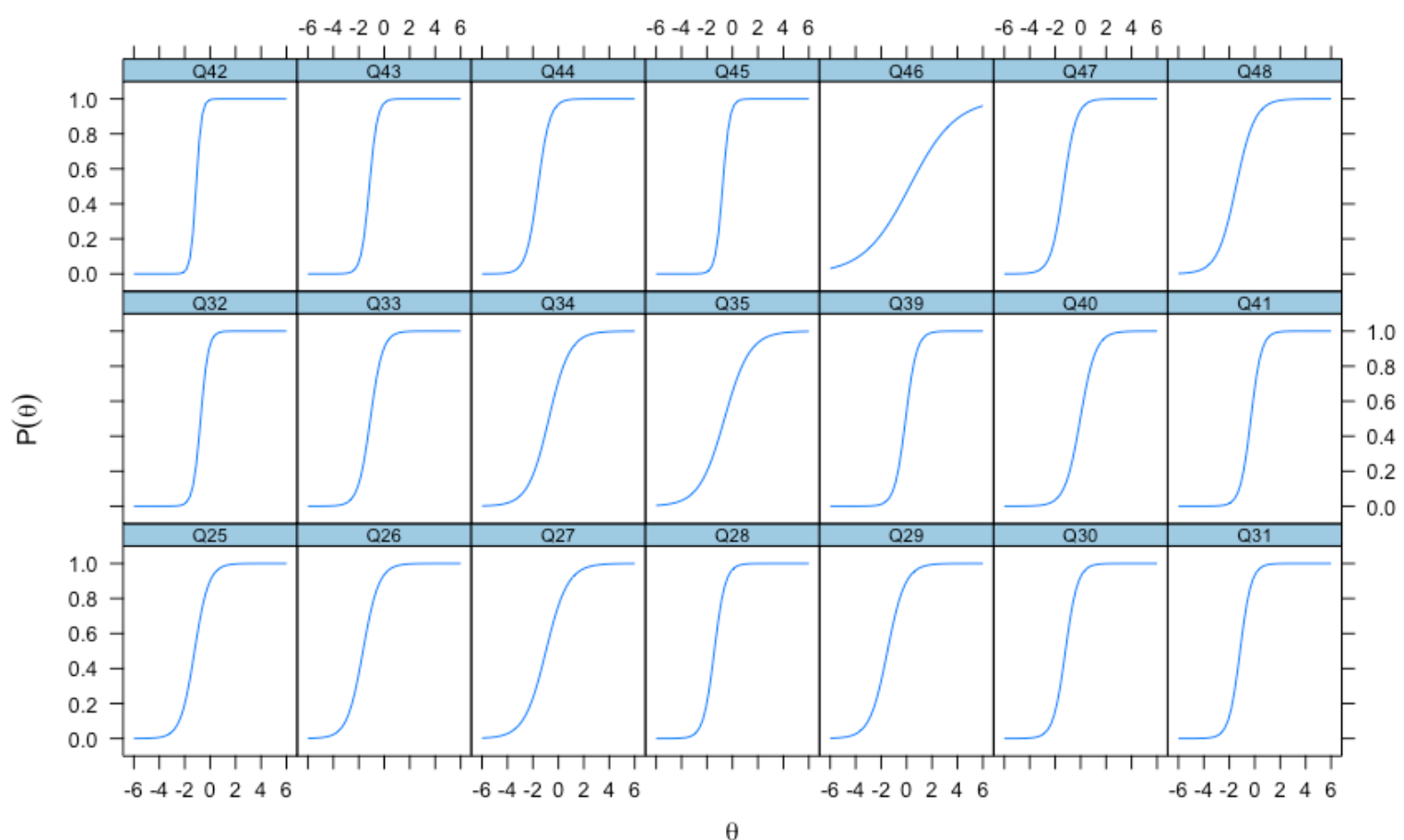


Figure 3

Item Characteristic Curves (ICC) for different age group

\section{Item trace lines}

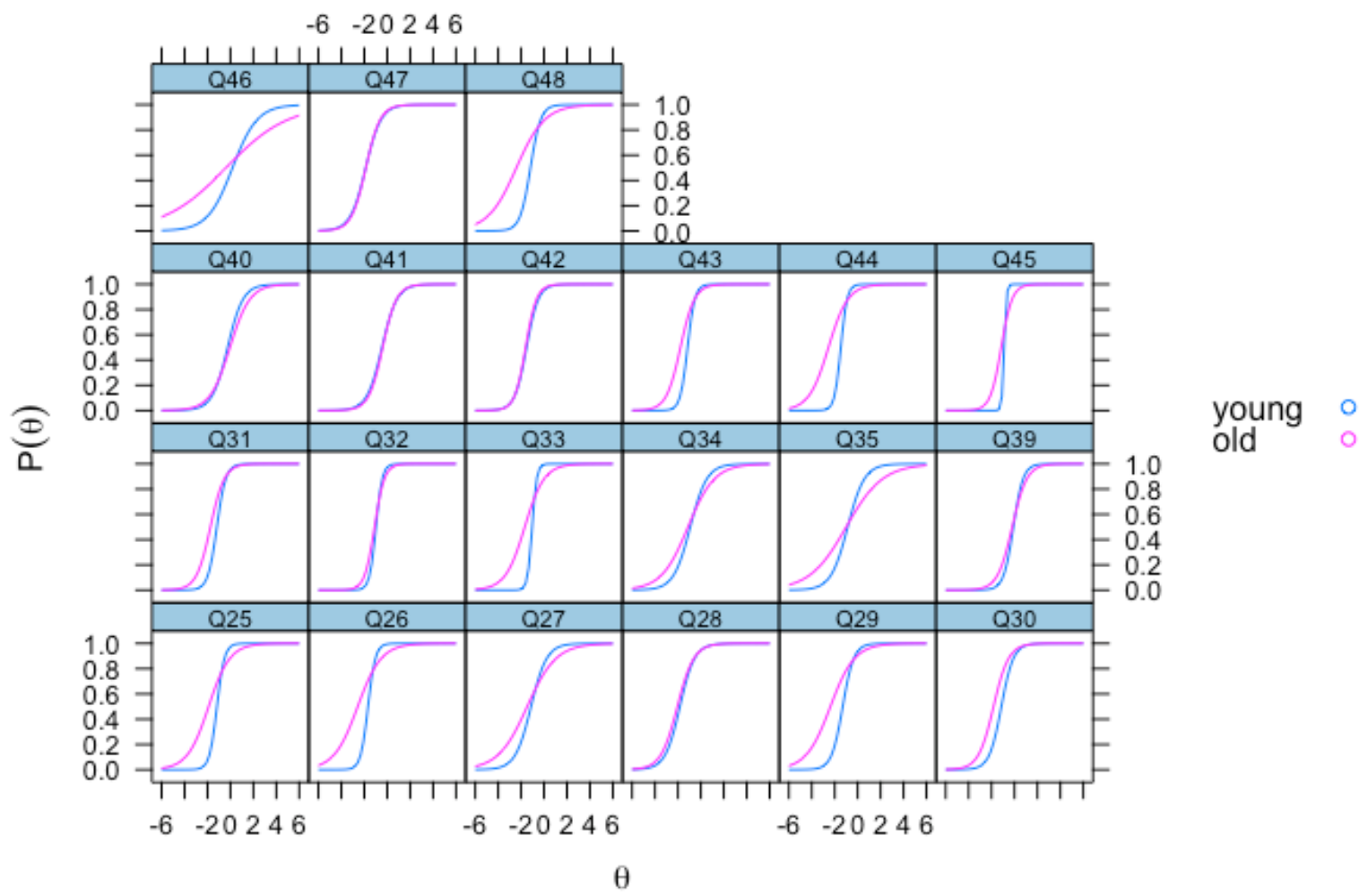




\section{Figure 4}

Item Characteristic Curves (ICC) for different gender group

\section{Item trace lines}

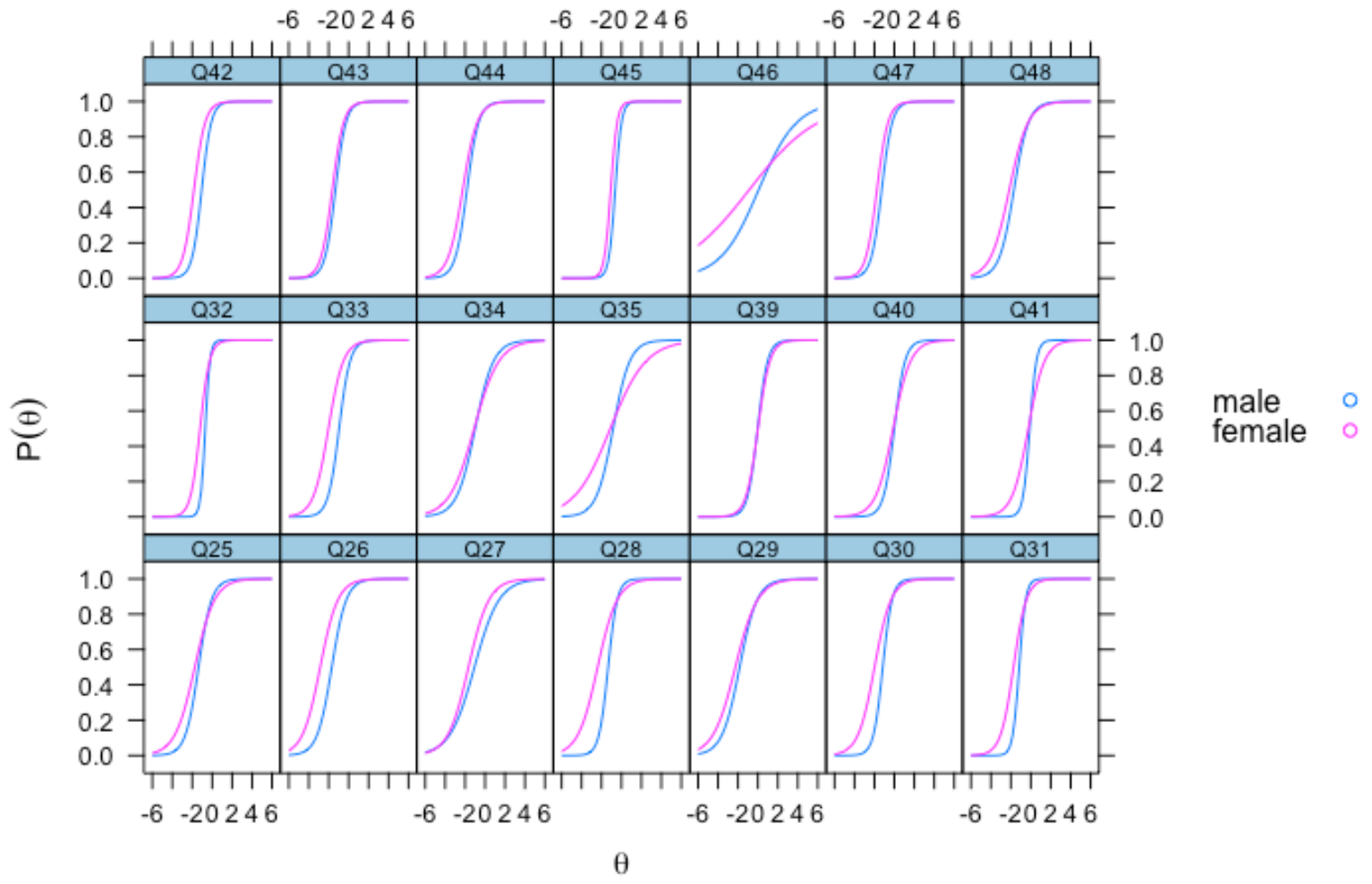

